\title{
Apropriação Linguística e Significado em Atividades de Modelagem Matemática
}

\section{Linguistic Appropriation and Meaning in Mathematical Modeling Activities}

\author{
Bárbara Nivalda Palharini Alvim Sousa* \\ ORCID iD 0000-0002-3712-9663 \\ Lourdes Maria Werle de Almeida ${ }^{* *}$ \\ ORCID iD 0000-0001-8952-1176
}

\begin{abstract}
Resumo
Neste artigo dirigimos nossa atenção para os diferentes jogos de linguagem associados ao desenvolvimento de atividades de Modelagem Matemática e os significados constituídos pelos alunos no interior destes jogos de linguagem em relação a equações diferenciais ordinárias de primeira ordem. A pesquisa está fundamentada na Modelagem Matemática na Educação Matemática e tem como base filosófica os estudos de Ludwig Wittgenstein e de alguns de seus interpretadores. Considerando esses elementos teórico-filosóficos, atividades de modelagem matemática foram desenvolvidas em um curso de Licenciatura em Matemática na disciplina de Equações Diferenciais Ordinárias. Os dados foram coletados por meio de registros escritos, gravações em áudio e vídeo, questionários e entrevistas. A metodologia de análise dos dados considera as práticas discursivas dos alunos e possibilita a construção de árvores de associação de ideias a partir destas. Os resultados indicam que a constituição de significado no interior de atividades de modelagem está associada à apropriação linguística dos alunos relativa às regras e técnicas que estão configuradas em jogos de linguagem específicos identificados nas atividades de Modelagem Matemática.
\end{abstract}

Palavras-chave: Educação Matemática. Modelagem Matemática. Jogos de Linguagem. Wittgenstein.

\begin{abstract}
In this paper we turn our attention to the different language games associated to the development of Mathematical Modelling activities and to the meanings constituted by students within these language games in relation to the first order ordinary differential equations. The research is based on Mathematical Modelling in Mathematics Education and has as its philosophical basis the studies of Ludwig Wittgenstein and some of his interpreters. Considering these theoretical-philosophical elements, mathematical modelling activities were developed in a Mathematics Degree in a course of Ordinary Differential Equations. Data were collected through written records, audio and video recordings, questionnaires, and interviews. The data analysis methodology considers the students' discursive practices and allowed us to construct trees of idea association. The results indicate that the constitution of meaning within modelling activities is associated to the students' linguistic appropriation of the rules and techniques that are configured in specific language games identified in the Mathematical Modelling activities.
\end{abstract}

Keywords: Mathematics Education. Mathematical Modelling. Language Games. Wittgenstein.

\footnotetext{
* Doutora em Ensino de Ciências e Educação Matemática pela Universidade Estadual de Londrina (UEL). Docente na Universidade Estadual do Norte do Paraná (UENP), Cornélio Procópio, Paraná, Brasil. Endereço para correspondência: Rua Fermino Barbosa, 50, apto 1103, Aurora, Londrina, Paraná, Brasil, CEP: 86047-480. Email: barbara.palharini@uenp.edu.br.

** Doutora em Engenharia de Produção pela Universidade Federal de Santa Catarina (UFSC). Docente da Universidade Estadual de Londrina (UEL), Londrina, Paraná, Brasil. Endereço para correspondência: Rua Antônio Pisicchio, 155, apto 303, CEP: 86050-482, Londrina, Paraná, Brasil. E-mail: lourdes.maria@ sercomtel.com.br.
} 


\section{Introdução}

No âmbito do ensino e da aprendizagem de Matemática, a linguagem matemática atua como uma das causas de estranhamento dos alunos, considerando sua natureza convencional e normativa e suas especificidades no ato de comunicar. Neste contexto, faz-se importante a investigação das influências dos processos linguísticos que emergem em sala de aula, em particular, os usos da linguagem matemática, por professores e alunos, e o papel dos métodos de ensino no processo de aprendizagem. Gottschalk (2010, p. 64) enfatiza que o método de ensino no processo de aprendizagem deve atuar como "meio de apresentação de nossas convenções linguísticas".

Com base na perspectiva wittgensteiniana de linguagem é possível dizer que, de modo geral, a atividade matemática está relacionada à apropriação linguística de regras e proposições matemáticas que determinam as possibilidades de ação dos sujeitos nos diferentes jogos de linguagem $^{1}$ que circundam o ambiente escolar. A interlocução destes diferentes jogos de linguagem na Educação Matemática é sugerida por alternativas pedagógicas que visam habilitar os sujeitos a lidar com diferentes situações do cotidiano em que necessitam da Matemática ou com aquelas em que eles podem se beneficiar com o seu uso.

Nessa pesquisa, temos como base filosófica a concepção jogos de linguagem de Wittgenstein (2013) em que significado e verdade só podem ser considerados no âmbito de uma prática especifica e entendemos que, quando os sujeitos estão engajados em atividades de Modelagem Matemática, diferentes jogos de linguagem são acionados ou requeridos.

Com origem em situações, de modo geral, empíricas, as atividades de Modelagem Matemática estão sujeitas a uma pluralidade de linguagens, regras e proposições advindas das diferentes práticas por meio dos usos de conceitos matemáticos.

Considerando a importância da problematização dos usos da linguagem, da linguagem matemática, dos procedimentos e das regras que emergem em atividades de Modelagem, neste artigo dirigimos nossa atenção para os diferentes jogos de linguagem associados ao desenvolvimento de atividades de Modelagem Matemática e os significados constituídos pelos alunos no interior destes jogos de linguagem em relação a equações diferenciais ordinárias de primeira ordem. Para tanto, inicialmente, apresentamos elementos das bases teóricas que

\footnotetext{
${ }^{1}$ Em Wittgenstein $(2013, \S 23)$, as expressões jogo de linguagem e forma de vida são detalhadas e exemplificadas por meio de diferentes exemplos ou usos da linguagem, "a expressão "jogo de linguagem" deve salientar aqui que falar uma língua é parte de uma atividade ou de uma forma de vida”. Diferentes jogos de linguagem denotam práticas específicas, por exemplo, a representação teatral está associada a um jogo de linguagem de uma forma de vida específica às artes, em que cenas e cenários visam encenar dramas, romances, suspenses, entre outros.
} 
fundamentam a nossa interpretação sobre os dados coletados em uma pesquisa empírica desenvolvida com treze alunos de um curso de Licenciatura em Matemática, na disciplina de Equações Diferenciais Ordinárias.

O processo analítico que empreendemos leva em consideração seis atividades de Modelagem Matemática desenvolvidas por estes alunos e os jogos de linguagem associados a estas atividades. Registros dos alunos relativos às atividades desenvolvidas, diálogos entre eles, bem como as entrevistas realizadas, fornecem indícios da linguagem em ação no decorrer das atividades.

\section{Modelagem Matemática na Educação Matemática}

Henry Pollak, um dos precursores da Modelagem Matemática, já sinalizava que “experiências com modelagem matemática são muito valiosas para os alunos, pois, além de seu valor pedagógico possibilitam ao aluno conhecer aplicações da matemática em diferentes situações" (POLLAK, 1979, p. 240, tradução nossa).

Na visão de Pollak (2015), o desenvolvimento de atividades de Modelagem Matemática requer formular uma situação-problema, decidir o que manter e o que ignorar na criação de um modelo, fazer uso de Matemática na situação idealizada e, então, decidir se os resultados fazem sentido face à situação original. A situação idealizada, neste contexto, incorpora simplificações da situação real e decorre da idealização em que um problema passível de abordagem matemática é formulado a partir da situação real. Tem-se discutido na literatura que os alunos que desenvolvem a atividade de modelagem precisam decidir quais são os aspectos importantes, da situação-problema, a fim de mantê-los na formulação da situação idealizada (ALMEIDA, 2018; STILLMAN et al. 2015).

Tomando como ponto de partida as ações dos alunos, em uma atividade de Modelagem Matemática, na sala de aula, a dinâmica da atividade, de modo geral, se inicia com uma situação-problema que pode ser indicada pelos professores, ou definida pelos alunos. No entanto, Stillman, et al. (2015, p. 95-96, tradução nossa) ponderam que o desenvolvimento de atividades de Modelagem Matemática deve contemplar dois aspectos:

[...] a elaboração do modelo matemático para a situação por meio de questões matemáticas e artefatos matemáticos (por exemplo, gráficos e tabelas) utilizados na formulação do modelo matemático. Depois os resultados matemáticos (isto é, as respostas) devem, então, ser interpretadas em termos da situação idealizada e da situação real que estimulou a Modelagem (isto é, de volta para o domínio extramatemático). 
Pollak (2012, p. xi, tradução nossa) enfatiza a importância de, em atividades de Modelagem Matemática, não se considerar apenas a resolução do problema, mas também a sua formulação:

\begin{abstract}
O coração da modelagem matemática [...] é a formulação de problemas antes da resolução destes. Tantas vezes em Matemática dizemos "provar o seguinte teorema" ou "resolver o seguinte problema". Quando começamos neste ponto, estamos ignorando o fato de que encontrar o teorema ou o problema certo já é grande parte da batalha. Ao enfatizar o aspecto da formulação do problema, a modelagem matemática traz de volta à Educação Matemática a formulação de problemas, bem como a sua resolução.
\end{abstract}

Assim, a experiência com a Matemática, como considera Pollak (2012), se constitui na medida em que formulação e resolução de problemas se complementam. Podemos considerar, portanto, que o uso dos conceitos matemáticos é fundamental em atividades de Modelagem Matemática.

No desenvolvimento da atividade, a partir da formulação de hipóteses e da elaboração do modelo matemático, diferentes conceitos ou procedimentos matemáticos são utilizados com a finalidade de oferecer alguma resposta ao problema identificado na situação em estudo. Neste sentido, para além da linguagem associada a cada situação em particular, a linguagem matemática, suas regras e proposições devem ser empregadas. Neste artigo, direcionamos nossa atenção para linguagem, considerando que, como argumenta Vilela (2009, p. 197), a diversidade da linguagem passa a ser investigada na prática, pois ela se constituiu dos elementos pelos quais expressamos nossos conhecimentos e falamos das coisas que existem. Esta diversidade de usos da linguagem nos remete a ideias da perspectiva wittgensteiniana de linguagem.

\title{
3 Perspectiva wittgensteiniana de linguagem e a Matemática
}

A filosofia da linguagem é vista como ulterior a qualquer atividade filosófica: "é a partir da Filosofia da Linguagem, isto é, da análise crítica da estrutura, dos limites e das possibilidades da nossa linguagem quotidiana, que poderemos estabelecer corretamente questões de teoria do conhecimento, política, ontologia, etc.” (CONDÉ, 1998, p. 17). O filósofo contemporâneo, Ludwig Wittgenstein trata da filosofia da linguagem amparado na concepção jogo de linguagem em que o exame, em particular, da Matemática ocorre por meio da consideração do papel que a Matemática desempenha em nossas vidas, bem como do seu relacionamento especial com outros jogos de linguagem (GERRARD, 1991).

Segundo Miguel (2014, p. 24), “conhecimentos fluem nos jogos de linguagem, isto é, 
são neles encenados, através de um mecanismo de interações e composições de outras práticas". Desse modo, os conhecimentos são contextualizados, estão associados a diferentes jogos de linguagem.

E, neste contexto, o significado está associado ao uso das palavras. De acordo com Wittgenstein (2013), a palavra sozinha parece morta. O que lhe confere vida? - Ela está viva no uso.

Assim, os significados são constituídos no uso, em diferentes jogos de linguagem, os quais, por sua vez, são associados a conjuntos particulares de regras. As experiências dos sujeitos são, nesta perspectiva, constituídas a partir de um processo de apropriação linguística, como pondera Moreno (2003):

É no interior desse conjunto de regras conceituais, as diferentes gramáticas, que são construídos os diversos sentidos da experiência, ou melhor, é de acordo com essas regras que construímos raciocínios, juízos, hipóteses, descrições e inferências ao combinarmos os conceitos, e que adquirimos, também, certezas e dúvidas [...] Os conteúdos da experiência, em geral, são, nesse sentido, o resultado de um longo e complexo processo de apropriação linguística (MORENO, 2003, p. 116).

Neste contexto, a linguagem é vista como constitutiva do significado das coisas que se dá por meio de usos das palavras e de regras, regidas por uma gramática ${ }^{2}$. Em situações de ensino e de aprendizagem lidamos com o uso de diferentes regras, que muitas vezes podem ser comparadas a técnicas para o uso de expressões, para o cálculo com equações matemáticas, entre outros. É por meio da descrição das regras, ou por meio de exemplos, que os outros podem aprender a seguir estas regras e indícios do entendimento do outro podem ser vistos em suas ações. Ao considerar uma perspectiva pragmática do ensino e da aprendizagem no contexto escolar, o professor é aquele que introduz as regras e os usos convencionados da linguagem matemática, por meio do que Wittgenstein caracteriza como treino, ou seja, instruções para os usos das regras.

No que se refere à Matemática, Wittgenstein (1996) argumenta que a Matemática é normativa. Segundo Gottschalk (2004, p. 2), "se atentarmos para o uso que fazemos de seus enunciados, constataremos que eles têm uma função normativa, ou seja, dizem-nos o que tem sentido ou o que não têm sentido dizer”. E, segundo a mesma autora, as proposições matemáticas são, nesta perspectiva, normativas, pois se tornam condições de significado para a atividade matemática.

Podemos, neste contexto, retomar as palavras de Wittgenstein (1996, p. 381, tradução nossa) sobre Matemática: “A Matemática - quero dizer-lhe, ensina, não apenas a resposta a uma

\footnotetext{
${ }^{2}$ Segundo Moreno (2003), o termo gramática pode ser entendido como o conjunto de usos que fazemos das palavras, os quais podem ser expressos sob a forma de um sistema de regras.
} 
pergunta, mas todo um jogo de linguagem com perguntas e respostas". Além disso, a própria Matemática se constitui como um jogo de linguagem, "uma atividade que entrelaça símbolos linguísticos e técnicas compartilhadas por uma comunidade" (GOTTSCHALK, 2004, p. 331). Neste jogo de linguagem, a Matemática não descreve a realidade, mas dá aos sujeitos condições para a compreensão nos diferentes contextos. A linguagem matemática, por sua vez, embora de natureza gramatical, de natureza normativa, pode admitir usos empíricos, dependendo do contexto em que ela será utilizada.

A atividade matemática dos alunos está associada ao domínio de técnicas, ao seguir regras e ao uso das proposições matemáticas de acordo com o emprego convencionado na comunidade. Para Gottschalk (2010, p. 79), “à medida que somos capazes de aplicar a regra em diferentes circunstâncias, no interior de determinados jogos de linguagem, é que podemos começar a falar em aprendizado como uma atividade linguística, ou seja, ter aprendido é ser capaz de seguir regras da linguagem em diferentes contextos de aplicação”.

Neste artigo, a partir destas considerações, dirigimos nossa atenção para a linguagem e os usos da linguagem realizados por alunos quando desenvolvem atividades de modelagem matemática ao longo de aulas de uma disciplina de Equações Diferenciais Ordinárias. Interessanos olhar para os jogos de linguagem associados ao desenvolvimento de atividades de Modelagem em que equações diferenciais são utilizadas e como os significados são constituídos no decorrer desse desenvolvimento. Isto requer olhar para o uso de regras e de procedimentos associados à conceitualização e resolução de equações diferenciais, mas também a olhar para o uso destas equações no estudo de situações não matemáticas. Na perspectiva apontada por Moreno (2003), isto requer considerar o processo de apropriação linguística dos alunos ao desenvolver atividades de Modelagem Matemática.

\section{Aspectos metodológicos}

Com a finalidade de olhar para a apropriação linguística dos alunos em relação às regras, procedimentos e usos de equações diferenciais ordinárias quando desenvolvem atividades de Modelagem Matemática, realizamos uma pesquisa empírica em que atividades de Modelagem foram desenvolvidas no decorrer de uma disciplina de Equações Diferenciais Ordinárias (EDO), ministrada por uma das autoras deste texto, em um curso de Licenciatura em Matemática.

Os dados predominantemente descritivos, advindos das atividades de Modelagem desenvolvidas pelos alunos, foram coletados por meio dos registros escritos dos alunos, de 
gravações em áudio e vídeo e da aplicação de questionários e realização de entrevistas.

Neste artigo levamos em consideração seis atividades desenvolvidas no primeiro semestre da disciplina, quando o conteúdo ministrado era relativo às equações diferenciais ordinárias de primeira ordem e suas aplicações. Neste semestre, treze alunos frequentaram as aulas. Estas atividades foram desenvolvidas por três grupos de alunos: Grupo $1(\mathrm{G} 1)$ - alunos A1, A2, A3, A4; Grupo 2 (G2) - alunos B1, B2, B3, B4; Grupo 3 (G3) - alunos C1, C2, C3, C4, C5. Nas duas primeiras atividades, a situação a ser estudada foi sugerida pela professora e nas demais os próprios alunos escolheram uma situação-problema de seu interesse para investigar, conforme indica o Quadro 1.

Nas atividades AT1, AT2, AT5 e AT6 a situação referia-se a problemas de variação de temperatura. Nestes casos a situação conduziu ao uso de EDOs lineares de primeira ordem. Na atividade AT3, os alunos investigaram a velocidade de um ônibus espacial usando uma EDO separável e a análise dos dados se deu com base em conceitos matemáticos da Educação Básica. $\mathrm{Na}$ atividade AT4 o interesse dos alunos era determinar o tempo necessário para o esvaziamento de um silo, por meio da interpretação do fenômeno e da aplicação de uma EDO separável. A descrição detalhada destas atividades está em Palharini (2017).

\begin{tabular}{|c|c|c|c|}
\hline Código & Grupos & $\begin{array}{c}\text { Escolha da } \\
\text { situação }\end{array}$ & Tema da atividade \\
\hline AT1 & G1, G2, G3 & Professora & O resfriamento da cerveja \\
\hline AT2 & G1, G2, G3 & Professora & $\begin{array}{c}\text { A temperatura do café e a garrafa } \\
\text { térmica }\end{array}$ \\
\hline AT3 & G1 & Alunos & Ônibus espacial \\
\hline AT4 & G1 & Alunos & Armazenamento de grãos de soja \\
\hline AT5 & G2 & Alunos & $\begin{array}{c}\text { Variação da temperatura na } \\
\text { produção do sorvete }\end{array}$ \\
\hline AT6 & G3 & Alunos & $\begin{array}{c}\text { Preparo da gelatina: variação da } \\
\text { temperatura da gelatina em relação } \\
\text { ao tempo }\end{array}$ \\
\hline
\end{tabular}

Quadro 1 - Atividades de modelagem matemática desenvolvidas pelos alunos Fonte: As autoras (2017).

A análise dos dados se deu de forma interpretativa, considerando o uso de regras e proposições em atividades de Modelagem Matemática visando inferir sobre os significados constituídos pelos alunos e associados a um processo de apropriação linguística relativo às equações diferenciais de primeira ordem, bem como o seu papel em problemas investigados em atividades de Modelagem Matemática.

$\mathrm{Na}$ análise dos dados, nos referimos à linguagem em uso e às práticas discursivas dos alunos no desenvolvimento das atividades de Modelagem Matemática, conforme indicações de Spink (2013). Para essa autora, as práticas discursivas consistem na linguagem em ação e indicam o posicionamento das pessoas nas relações com os outros bem como a sua capacidade 
de argumentação. Assim, podemos considerar que estas práticas refletem conhecimentos que fluem nos jogos de linguagem e são neles (nos jogos de linguagem) encenados, conforme considera Miguel (2014).

Para elucidar o que nossa interpretação à luz dos pressupostos teóricos usados nos permite inferir, usamos o recurso analítico indicado em Spink (2013), como árvores de associação de ideias. Segunda essa autora, estes esquemas permitem visualizar o fluxo da associação de ideias sugeridas pelos dados coletados.

\section{As atividades de Modelagem Matemática desenvolvidas e a apropriação linguística dos alunos}

Neste artigo, levamos em consideração seis atividades desenvolvidas no primeiro semestre da disciplina de Equações Diferenciais Ordinárias quando o conteúdo ministrado era relativo às equações diferenciais ordinárias de primeira ordem e suas aplicações.

O desenvolvimento da disciplina, campo da pesquisa empírica aqui declarada, abrange aulas expositivas em que regras relativas à conceitualização e aos procedimentos de resolução de EDOs de primeira ordem eram apresentadas e discutidas com os alunos, bem como aulas práticas para o emprego dessas regras em diferentes situações advindas de contextos de interesse dos alunos. As aulas práticas são aquelas em que as atividades de Modelagem Matemática foram desenvolvidas pelos grupos de alunos.

Em cada atividade de Modelagem Matemática, uma situação-problema foi estudada por meio de uma situação matemática idealizada, conforme aponta Almeida (2018). As situações estão descritas no Quadro 2.

\begin{tabular}{|c|c|c|}
\hline $\begin{array}{c}\text { Quanto tempo a cerveja deve } \\
\text { ficar em resfriamento para } \\
\text { alcançar a temperatura desejada? }\end{array}$ & $\begin{array}{c}\text { Com base na coleta de dados } \\
\text { relativos à temperatura do café } \\
\text { em uma garrafa térmica no } \\
\text { decorrer de uma hora, como } \\
\text { obter a temperatura do café, } \\
\text { nesta mesma garrafa térmica, } \\
\text { em um instante qualquer? }\end{array}$ & $\begin{array}{c}\text { A partir de dados do perfil de } \\
\text { aceleração do ônibus espacial STS } \\
\text { 121, durante a fase de subida, como } \\
\text { determinar a velocidade do ônibus } \\
\text { espacial em um instante qualquer no } \\
\text { intervalo de 0 a 540 segundos? }\end{array}$ \\
$\begin{array}{c}\text { AT1 - adaptada de Parolin, } \\
\text { Soares J Johansson (2006) }\end{array}$ & $\begin{array}{c}\text { AT2 Desenvolvida por G1, G2 } \\
\text { esenvolvida por G1, G2 e G3 }\end{array}$ & AT3 Desenvolvida por G1 \\
\hline $\begin{array}{c}\text { Considerando dados coletados } \\
\text { em uma cooperativa industrial, } \\
\text { qual o volume de grãos no } \\
\text { interior de um silo em um } \\
\text { instante t qualquer? Qual o } \\
\text { tempo necessário para esvaziar } \\
\text { este silo? }\end{array}$ & $\begin{array}{c}\text { Com base em um experimento, } \\
\text { como obter a temperatura do } \\
\text { sorvete no freezer, em qualquer } \\
\text { instante de tempo? }\end{array}$ & $\begin{array}{c}\text { Sabendo que a gelatina atinge a } \\
\text { consistência desejada a 4 }{ }^{\circ} \text { C, depois de } \\
\text { quanto tempo na geladeira a gelatina } \\
\text { estará pronta para consumo? }\end{array}$ \\
\hline
\end{tabular}

Quadro 2 - Situações-problema formuladas pelos alunos nas atividades de modelagem matemática 
Fonte: Registros dos alunos (2016).

Nossa atenção neste artigo dirige-se a estas situações idealizadas, considerando que o emprego de regras, sejam elas relativas à Modelagem Matemática, sejam elas relativas às equações diferenciais ordinárias, se deu no interior do estudo destas situações.

Neste sentido diferentes jogos de linguagem foram se estruturando e se associando, considerando o contexto de origem da situação, bem como aquele relativo ao campo da Matemática em que a solução para o problema foi construída pelos alunos.

No processo analítico em que olhamos para a apropriação linguística dos alunos, relativamente ao uso de regras no âmbito de EDOs de primeira ordem e de proposições empíricas, analisamos de forma conjunta as quatro atividades de modelagem em que as situações-problema envolvem problemas de variação de temperatura (AT1, AT2, AT5 e AT6). Separadamente olhamos para a atividade acerca da velocidade de um ônibus espacial e para a atividade referente ao armazenamento de grãos de soja em um silo.

Nas duas primeiras atividades de modelagem matemática (AT1 - sobre o resfriamento da cerveja e AT2 - sobre a variação da temperatura do café), a professora levou para a sala de aula os dados relativos às situações. Nestes casos, portanto, o jogo de linguagem do contexto da situação, já foi determinado antecipadamente, cabendo aos alunos a construção da experiência, como sugere Moreno (2003), a partir de acesso às regras já determinadas. O que os alunos fariam então é associar a esta variação de temperatura esperada para a cerveja e para o café, regras da Matemática. No entanto, estes alunos não tinham ainda experiência com atividades de Modelagem Matemática, de modo que a transição de linguagem da situação para a linguagem matemática não lhes era ainda uma regra conhecida.

Os alunos do grupo G3, por exemplo, não associaram, inicialmente, o problema da cerveja com algum procedimento ou conceito de EDO na atividade AT1. Ao invés disso, conseguiram fazer a interpretação dos dados utilizando uma função exponencial associada às temperaturas da cerveja no decorrer do tempo em que ela estava no congelador, conforme indica a Figura 1. Neste caso, a hipótese de que a situação pode ser associada uma função exponencial proporcionou a construção do modelo que viabilizou a obtenção do tempo necessário para a cerveja atingir uma temperatura desejada. 


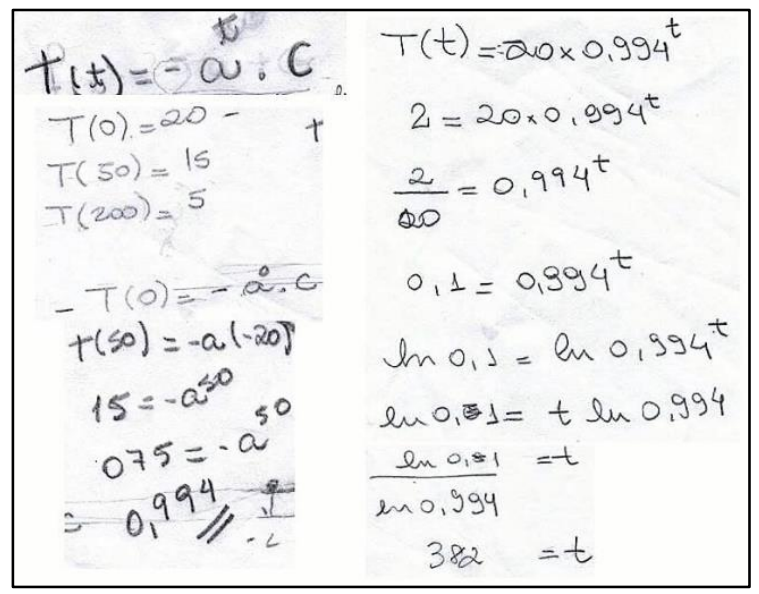

Figura 1 - Modelo Matemático G3 AT1

Fonte: Registros de G3 AT1 (2016).

Já na atividade AT2, relativa ao resfriamento do café na garrafa térmica, os alunos do grupo G1, inicialmente, construíram, com base em algumas representações dos dados da situação, a hipótese de que tratava-se de um comportamento linear, conforme indica parte de um diálogo entre os alunos e a professora:

A1: [...] Como a temperatura do café está tendendo à temperatura ambiente, pensamos que seria uma exponencial, mas ai observamos o seguinte:

[o alunos esboça um gráfico no quadro para exemplificar o raciocínio do grupo]

O que observamos, nesse pedaço aqui [ilustrando o espaço de tempo em que os dados foram coletados, ou seja, o domínio da função] é que podemos considerar apenas isso aqui, ai a gente fez o seguinte. Sabemos que a função do primeiro grau é isso aqui: $f(t)=a t+b$.

A4: É função linear, gente.

[o aluno resolve no quadro o problema e é solicitado pela turma que explique]

A1: vocês podem observar que lá no tempo 60, temos a temperatura 57.

Professora: Agora A1, podemos usar então qualquer uma das duas funções?

A3: Sim, eu tinha pensado que é porque a temperatura na tabela é baixa, ai dá para considerar que a variação é constante, e temos uma função linear.

[nesse momento A1 esboça no quadro um gráfico da função linear para a temperatura] (Registros dos alunos do grupo G1 na atividade AT2, 2016).

Neste caso, o jogo de linguagem da Matemática e o jogo de linguagem da situação parecem se conjugar de uma forma ainda não suficientemente esclarecida para esses alunos. $\mathrm{Ou}$ seja, a apropriação linguística relativa à analise da situação da variação da temperatura do café na garrafa parece não configurada, uma vez que um modelo linear não seria adequado para tratar do resfriamento do café nestas circunstâncias.

Estes dois grupos só passaram a associar o estudo destas duas situações com equações diferenciais, depois de intervenções da professora e de consulta às notas das aulas expositivas anteriores.

Os demais grupos, no desenvolvimento dessas duas atividades, fizeram analogias com atividades anteriores desenvolvidas nas aulas de EDO e utilizaram a Lei de Resfriamento de Newton (Figura 2) para interpretar os fenômenos de resfriamento da cerveja e do café. A ação 
destes grupos dá indícios de que o treino com resoluções de equações pode ter proporcionado o reconhecimento da regra relativa ao tipo de fenômeno em que esta lei pode ser utilizada. A Matemática, embora normativa, neste caso, admite uso empírico e, sobretudo, um uso compartilhado por uma comunidade (os alunos da disciplina de EDO).

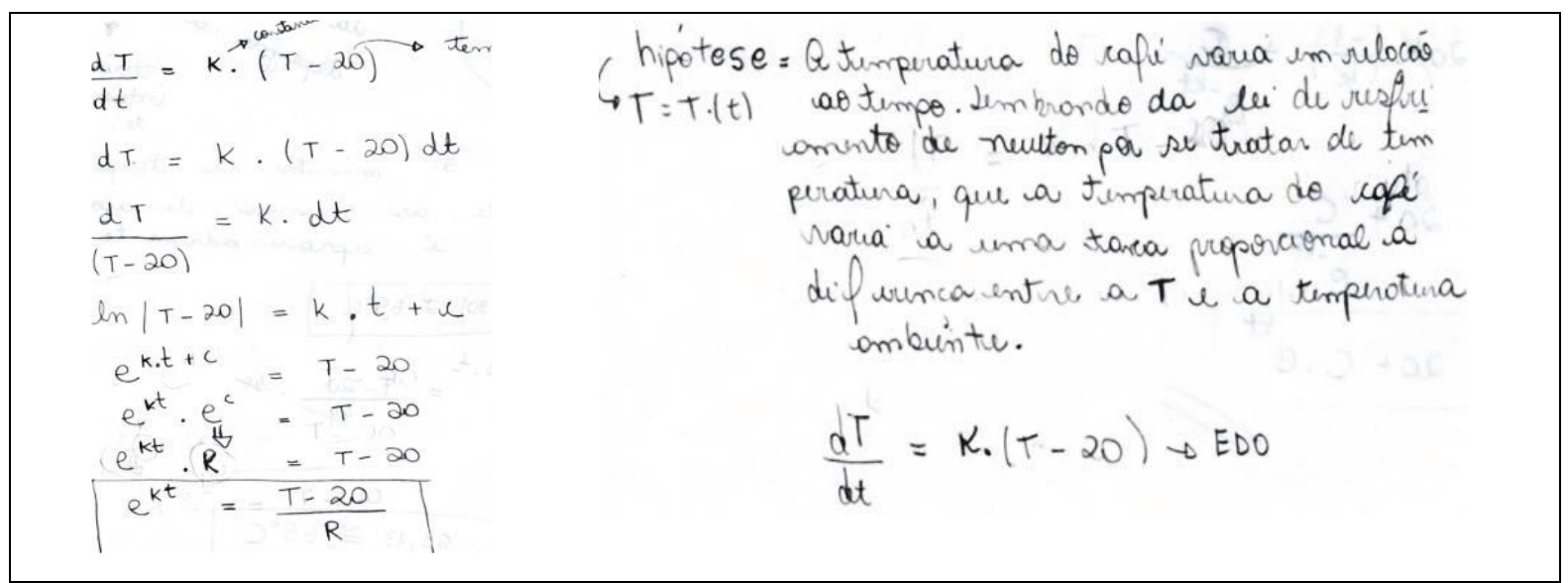

Figura 2 - Desenvolvimento matemático dos grupos G1 e G2 AT2

Fonte: Registros de G1 (à esquerda) e registros de G2 (à direita) da AT2 (2016).

Além destes usos, no momento em que os próprios alunos escolheram situaçõesproblema, os alunos dos grupos G2 e G3 escolheram situações com comportamentos semelhantes àqueles das duas atividades anteriores (AT5 e AT6). De fato, um grupo estudou a formação de consistência na gelatina, associada à temperatura da gelatina, e o outro grupo, a variação da temperatura na produção de sorvete. Se, por um lado, essa escolha pode representar uma apropriação do significado da lei de resfriamento de Newton, por outro lado pode representar uma limitação na compreensão das regras das equações diferenciais e suas aplicações, mantendo-se em situações em que as regras são as mesmas. Neste sentido, Pollak (2015) argumenta que a experiência com Modelagem Matemática e a experiência com conceitos matemáticos são interdependentes para o sucesso no desenvolvimento de atividades de Modelagem.

Como já observamos, o uso de situações semelhantes pode ser associado com a possibilidade de uso de regras já conhecidas, em consonância com a argumentação de Wittgenstein $(2013, \S 190)$ de que "é o modo como se têm a fórmula em mente que vai determinar quais passagens devem ser feitas". Qual é o critério para o modo como se tem a fórmula em mente? Talvez o modo como a usamos constantemente, o modo como nos foi ensinado a usá-la".

Neste sentido, o uso da fórmula (Lei de Resfriamento de Newton) em diferentes situações pode ter sido reflexo de um ensino de como usá-la, relativo às instruções da professora da disciplina de EDO, que inseriu as regras e técnicas associadas à resolução de equações 
diferenciais de primeira ordem.

No que se refere às atividades AT5 e AT6 em que os próprios alunos definiram a situação, os alunos imediatamente passaram a associar o estudo da situação com as regras configuradas na disciplina de EDO mediante as aulas da professora. Os jogos de linguagem a temperatura do sorvete e a consistência da gelatina - seriam agora postos em diálogo com os jogos de linguagem da Matemática em que as regras das EDOs estavam em processo de apropriação pelos alunos. Este diálogo está expresso na resolução dos alunos, conforme indica o Quadro 3.

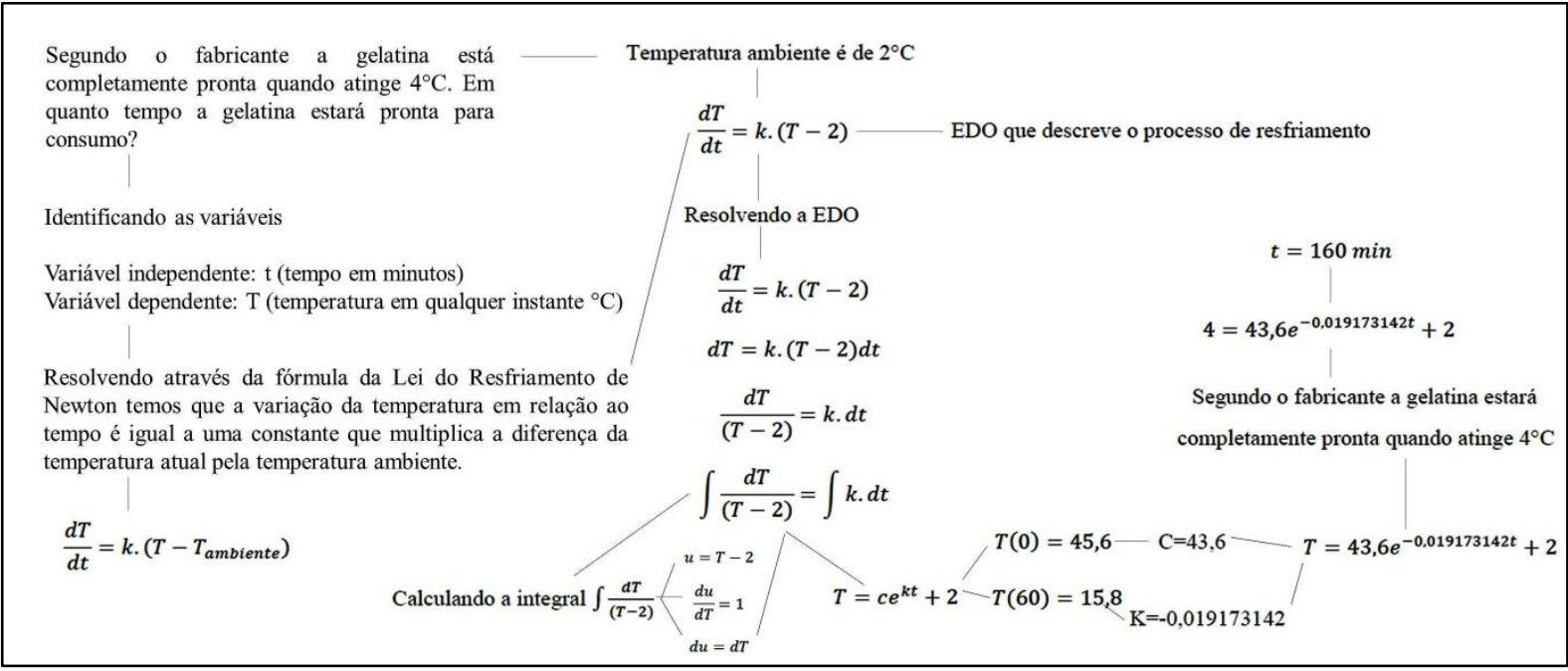

Figura 3 - A resolução da atividade AT6 pelos alunos do grupo G3 Fonte: Registros dos alunos na atividade AT6 (2016).

Os registros da Figura 3 indicam a resolução da EDO $\frac{d T}{d t}=k(T-2)$ por meio da separação das variáveis $\mathrm{T}$ - temperatura - e $\mathrm{t}$ - tempo - . Neste caso, o procedimento matemático atua como uma regra que é colocada em prática após explicação da professora. Segundo Gottschalk (2008, p. 88):

[...] o que vai nos dar a essência de um conceito matemático é sua aplicação, pois é no momento do uso do conceito que nos conectamos com toda sua gramática. [...] as atividades e os procedimentos que acompanham o uso dos símbolos são de natureza convencional.

O uso convencional, citado por Gottschalk (2008) e feito pelos alunos no desenvolvimento da atividade, está associado à cadeia de proposições matemáticas com as quais os alunos precisam lidar para resolver a EDO decorrente da situação matemática idealizada por meio do método de separação de variáveis.

Também nestas atividades, os alunos utilizam a Lei de Resfriamento de Newton como uma regra matemática que dá direções de como seguir a partir daquele momento, conforme sinaliza o diálogo dos alunos na apresentação de suas resoluções para a turma:

A4: eu achei interessante em relação ao grupo anterior [G2] que os dois grupos partiram para 
a lei do resfriamento de Newton, e o interessante é que para eles a constante era negativa, já para vocês a constante negativa não funcionaria. Interessante também eu achei, que estamos vendo a aplicação dos vários métodos que a professora [...] está ensinando para nós. Primeiro fomos por fator integrante, vocês já foram por separação de variáveis.

C4: É a mesma fórmula com vários.

C2: No caso, o modelo foi praticamente o mesmo, só que foi alterado aquela questão da constante (Registros dos alunos em sala de aula, ano).

O uso recorrente da Lei do Resfriamento de Newton pode estar associado com a apropriação linguística deste conceito. Segundo Wittgenstein $(2013, \S 150)$, “[...] a gramática da palavra "saber" goza de estreito parentesco com a gramática das palavras "poder", "ser capaz". Mas também com a gramática da palavra "compreender" (“dominar" uma técnica)". Neste sentido, a constituição de significado para a EDO relativa à Lei de Resfriamento de Newton é mediada por estes diferentes jogos de linguagem em que, ora regras da Matemática orientam as ações dos alunos, ora a situação-problema requer o uso de determinadas regras. $\mathrm{O}$ que se pode inferir relativamente a estas quatro atividades no que diz respeito ao uso de regras em atividades de Modelagem Matemática está expresso na associação de ideias que se mostra na Figura 4.

No que se refere às duas outras atividades - AT3 e AT4- os alunos do grupo G1 investiram em situações de seu interesse, mas diferentes das anteriormente estudadas.

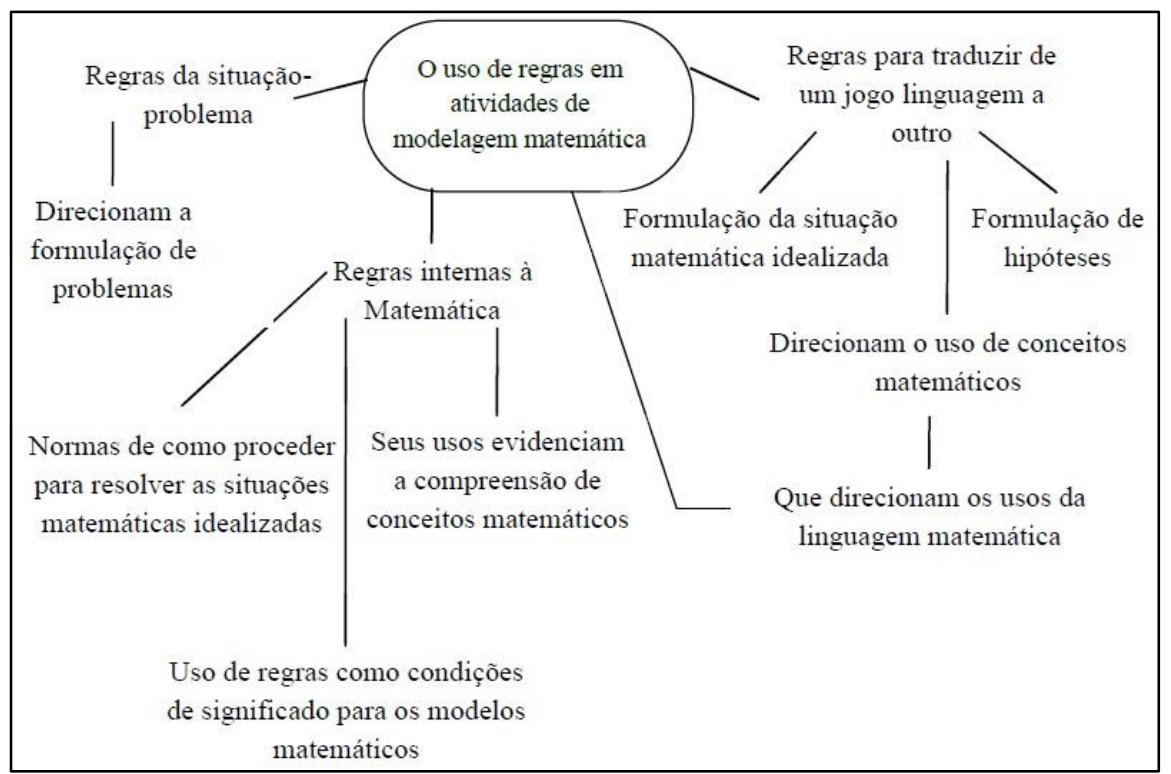

Figura 4 - Árvore de associação de ideias, o uso de regras em atividades de modelagem Fonte: Os autores (2017).

A árvore de associação de ideias da Figura 4 tem como raiz o uso de regras em atividades de modelagem matemática e este uso se ramifica não linearmente em diferentes usos e momentos da ação dos sujeitos durante a atividade de Modelagem Matemática. Três ramos principais direcionam o trabalho dos alunos nas diferentes faces da atividade: regras da 
situação-problema, regras internas à Matemática, regras para traduzir de um jogo de linguagem a outro. As regras da situação-problema auxiliam no design e na formulação de problemas, enquanto que as regras internas à matemática são colocadas pelos alunos como normas de como proceder para resolver as situações matemáticas idealizadas, como condições de significado para os modelos matemáticos.

Importante nesse item da árvore de associação de ideias está a relação com o ensino e a aprendizagem, por meio da associação das regras internas à Matemática com a indicação de que seus usos evidenciam a compreensão em matemática. As regras para tradução de um jogo de linguagem a outro servem como suporte aos alunos na formulação da situação matemática idealizada e das hipóteses que direcionam o trabalho dos alunos. E por meio do jogo de linguagem da tradução que o trabalho matemático dos alunos é direcionado, bem como os usos da linguagem matemática.

$\mathrm{Na}$ atividade de modelagem em que os alunos de G1 estavam interessados em estudar a velocidade de um ônibus espacial, usaram dados coletados em site da NASA. A partir de algumas simplificações e tratamentos dos dados, definiram uma hipótese que seria fundamental para o desenvolvimento da atividade: a variação do combustível, dos boosters, em relação ao tempo é linear, então a variação do combustível no tanque externo está relacionada à aceleração do ônibus espacial.

Nesta atividade, a imersão dos alunos no jogo de linguagem da situação não matemática requereu ações de simplificação para produzir uma situação idealizada que, no jogo de linguagem da Matemática, mais especificamente daquele da disciplina de EDO, se tornasse passível de interpretação matemática.

A hipótese definida pelos alunos a partir de seu olhar sobre os dados coletados seria, nesse caso, o fio condutor para determinar quais regras estariam no interior do jogo de linguagem da Matemática nesta atividade. Partindo então da representação gráfica da aceleração do ônibus espacial, recursos como ajuste de curvas, por exemplo, favoreceram a construção de um modelo matemático relacionado a esta representação, conforme indica a Figura 5. 


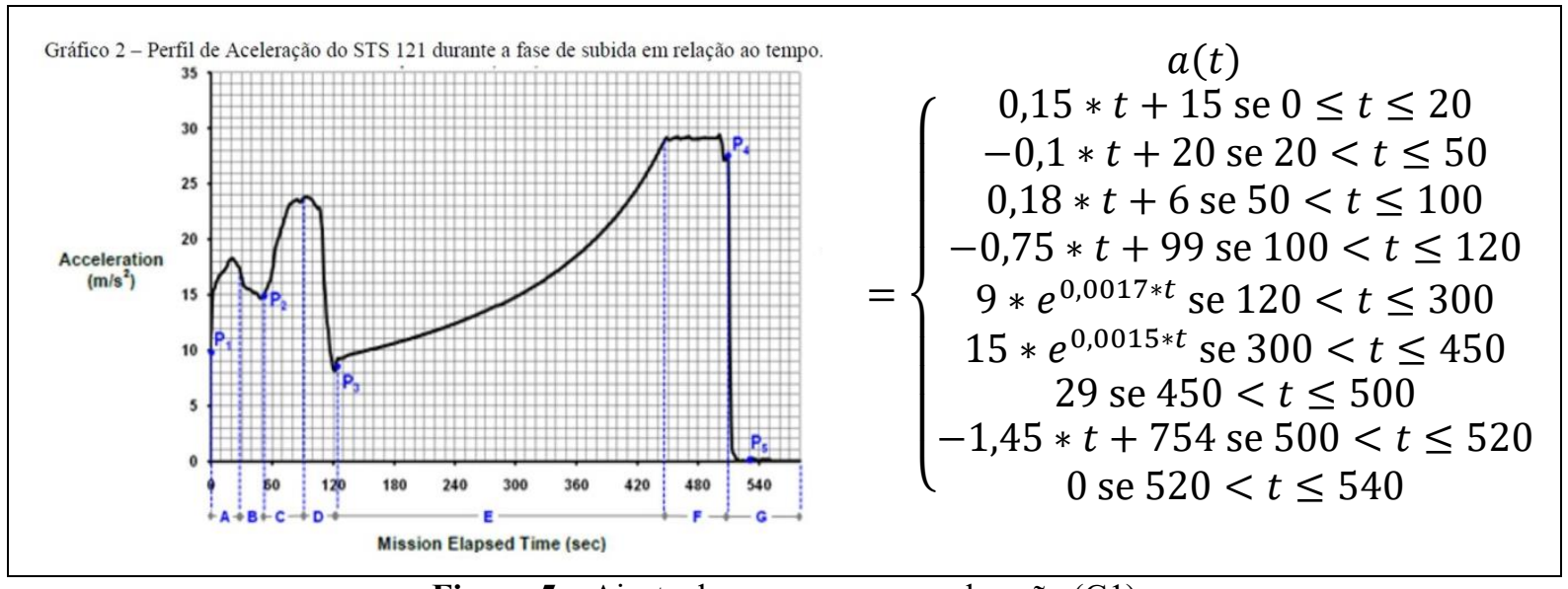

Figura 5 - Ajuste de curvas para a aceleração (G1)

Fonte: Registros dos alunos do grupo G1 na atividade AT3 (2016).

Uma vez determinada a aceleração, os alunos conheciam as regras para determinar a velocidade. Neste sentido, a linguagem matemática associada à situação trouxe mais luz para determinar as ações dos alunos, uma vez que já lhes era familiar o jogo de linguagem em que aceleração, velocidade, derivadas e integrais estão inseridas, de modo que determinaram as velocidades conforme indica a Figura 6.

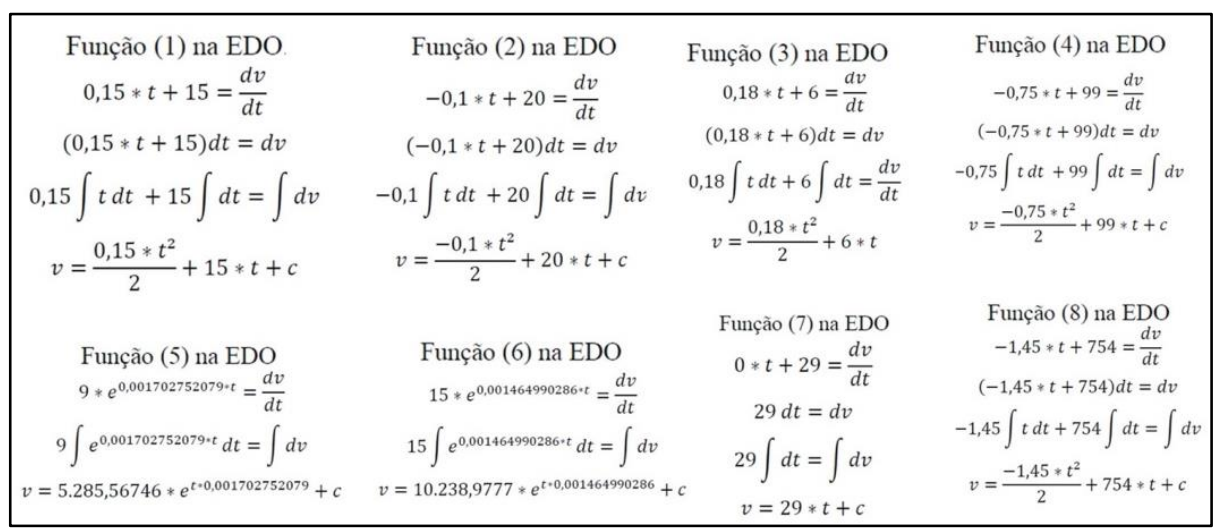

Figura 6 - A resposta do grupo para a velocidade no interior de um ônibus espacial Fonte: Registros dos alunos do grupo G1 na atividade AT3 (2016).

Os usos da Matemática na atividade AT3 sinalizam a relevância do treino, como caracterizado por Wittgenstein, uma vez que requerem a capacidade dos alunos de, além de transitar entre diferentes jogos de linguagem, ter o domínio de técnicas e regras específicas de cada jogo de linguagem. O significado para a velocidade do ônibus nesse caso não é independente do significado de derivada, de integral e de uma EDO separável. No sentido do que Wittgenstein (1996) pondera de que a Matemática nos ensina um jogo de linguagem com perguntas e respostas, a apropriação linguística de perguntas e respostas compartilhadas pela Matemática e pela situação nesta atividade proporcionou a obtenção da resposta para o problema que os alunos se propuseram a resolver nesta atividade de Modelagem.

É neste sentido que podemos ponderar que a EDO separável faz parte de um repertório 
de conhecimentos cujas regras são conhecidas pelos alunos. Para Gottschalk (2010, p. 79), “à medida que somos capazes de aplicar a regra em diferentes circunstâncias, no interior de determinados jogos de linguagem, é que podemos começar a falar em aprendizado como uma atividade linguística, ou seja, ter aprendido é ser capaz de seguir regras da linguagem em diferentes contextos de aplicação".

Em outra atividade de Modelagem Matemática (AT4), os alunos fazem uso de textos associados à mecânica de fluidos e traduzem a situação do volume de um silo, passo a passo para a linguagem matemática. A articulação entre as proposições empíricas e proposições matemáticas é feita pelos alunos e atua como constituinte de significado para uma EDO com condições específicas, conforme mostra o Quadro 4.

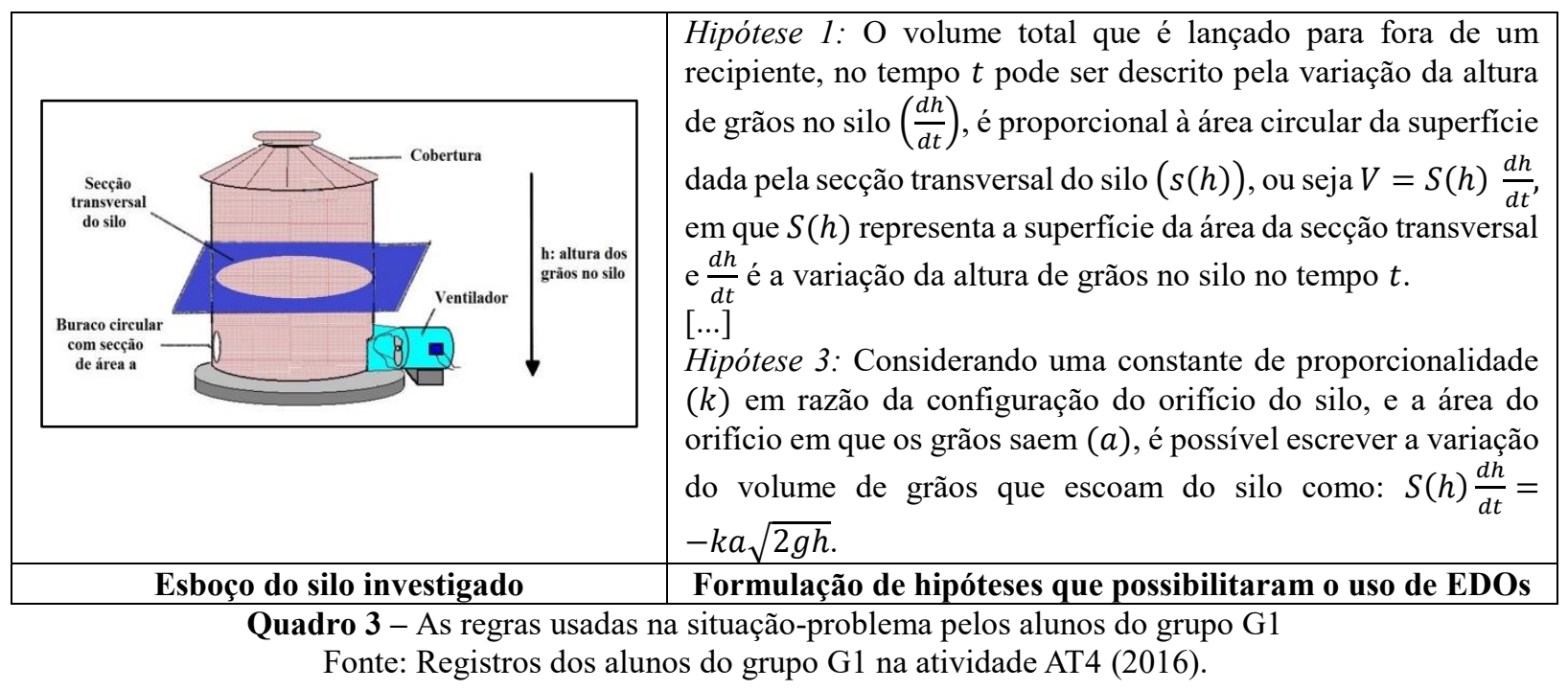

$\mathrm{O}$ seguir regras neste contexto é intrínseco à atividade de Modelagem Matemática. $\mathrm{Na}$ atividade AT4 para resolver as equações diferenciais do Quadro 3, os alunos do grupo G1 utilizaram o método de separação de variáveis e obtiveram que o tempo de esvaziamento do silo é dado por $t=\frac{2 \pi R^{2} \sqrt{h}}{a \sqrt{2 g}}+14,38 \mathrm{e}$, considerando as informações coletadas pelos alunos em uma cooperativa agroindustrial, concluíram que o tempo necessário para o esvaziamento total do silo é de aproximadamente sete dias.

O uso das equações diferenciais ordinárias de primeira ordem na abordagem de situações-problema está em sintonia com o que pondera Pollak (2012) de que não se pode avaliar somente a resolução do problema, mas também sua formulação. Nestes dois fazeres dos alunos é que a apropriação de regras em diferentes jogos de linguagem é requerida para constituir o significado neste contexto. É justamente neste aspecto que Stillman et al (2015) também defendem a necessidade de em atividades de Modelagem se evidenciar jogos de linguagem distintos, compreendendo o domínio da Matemática e aquele em que a situação- 
problema tem sua origem. É a possibilidade de compartilhar informações nestes diferentes jogos de linguagem que constitui a apropriação linguística, em consonância com a argumentação de Gottschalk (2004, p. 321) de que "aprender o significado de uma palavra pode consistir na aquisição de uma regra, ou um conjunto de regras, que governa seu uso em um ou mais jogos de linguagem". Este uso está fundamentado em regras internas à gramática da Matemática e da situação-problema em estudo. A Figura 7 ilustra como o uso em diferentes jogos de linguagem foi se configurando nas atividades de modelagem matemática que analisamos.

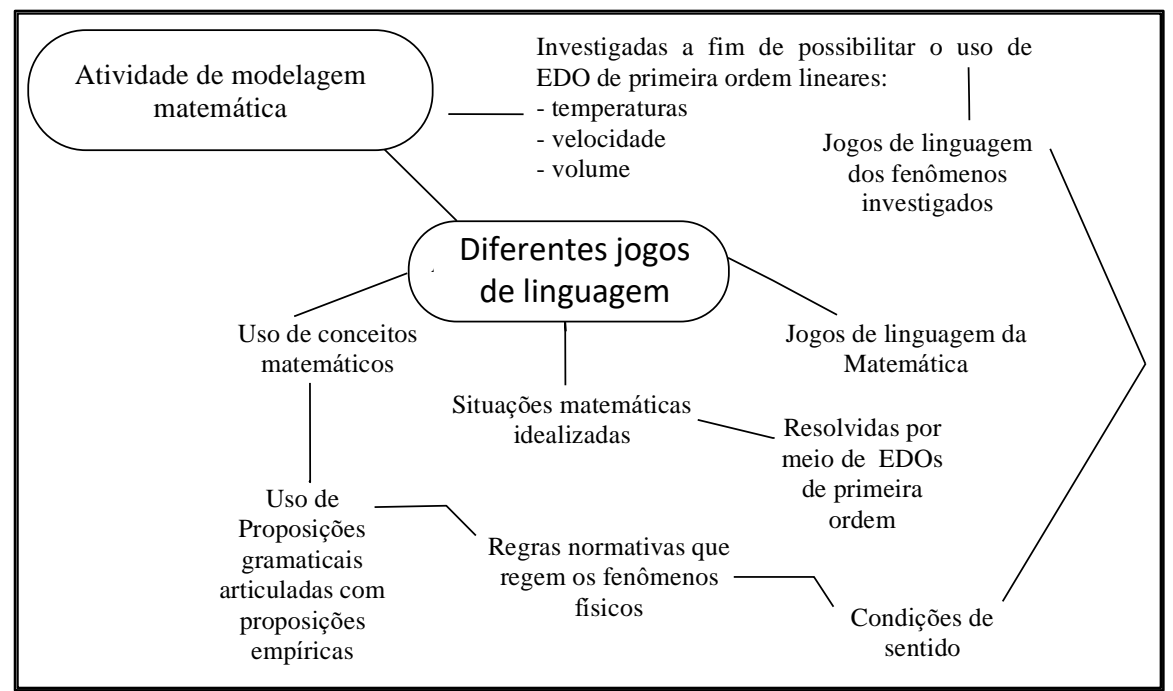

Figura 7 - Árvore de associação de ideias dos jogos de linguagem dos alunos Fonte: Registros dos alunos do grupo G1 na atividade AT4 (2017).

Os itens principais da árvore de associação de ideias da Figura 7 são destacados como Atividade de modelagem matemática e Atividade matemática. A associação entre os ramos da árvore visa evidenciar os jogos de linguagem dos alunos no desenvolvimento da atividade de Modelagem Matemática e no exercício da atividade matemática. Neste contexto, os jogos de linguagem dos fenômenos investigados nas atividades de Modelagem Matemática dizem respeito às diferentes possibilidades de uso das EDO de primeira ordem lineares por meio de problemas de temperatura, velocidade e volume e atuam como condições de sentido para que os alunos joguem com as regras normativas que regem os fenômenos físicos, e com o uso de proposições gramaticais articuladas com proposições empíricas associadas aos usos de conceitos matemáticos nas situações matemáticas idealizadas solucionáveis por meio de EDOs de primeira ordem.

\section{Considerações Finais}

Neste artigo dirigimos nossa atenção para os diferentes jogos de linguagem associados 
ao desenvolvimento de atividades de Modelagem Matemática e os significados constituídos pelos alunos no interior destes jogos de linguagem em relação a equações diferenciais ordinárias de primeira ordem. As nossas argumentações são subsidiadas por uma pesquisa empírica em que treze alunos desenvolveram seis atividades de Modelagem Matemática na disciplina de Equações Diferenciais Ordinárias.

Os usos do conceito matemático de equação diferencial ordinária de primeira ordem se deram na conexão deste conceito com outros conceitos matemáticos, na medida em que os alunos se familiarizavam com atividades de Modelagem Matemática de modo gradativo. E, nesse contexto, os alunos resolveram equações diferenciais ordinárias de primeira ordem separáveis e lineares, de modo que regras relativas aos métodos de resolução foram seguidas pelos alunos.

A análise das práticas discursivas dos alunos possibilitou a construção de árvores de associação de ideias acerca do uso normativo das regras em atividades de Modelagem Matemática, sendo estas: regras da situação-problema que direcionam a formulação de problemas; regras internas à Matemática, que indicam aos alunos normas de como proceder, e podem dar evidências aos professores a respeito da compreensão dos conceitos matemáticos por meio do emprego de técnicas, agindo também como condições de significado para os alunos; regras que atuam na tradução de um jogo de linguagem a outro, como a formulação da situação matemática idealizada e a formulação de hipóteses.

Podemos inferir que as situações em estudo em cada atividade de Modelagem Matemática desenvolvida foram sendo estudadas e compreendidas na medida em que diferentes jogos de linguagem se evidenciaram e os significados para o problema em estudo e para a Matemática usada na sua resolução foram sendo constituídos ao longo dos diferentes procedimentos relativos ao desenvolvimento da atividade. Os jogos de linguagem da Matemática serviram como fio condutor para a constituição de significados e para a articulação destes com as regras normativas que atuam na gramática dos fenômenos investigados, ou seja, que se constituem como condições para a constituição de significados para estes fenômenos.

Neste sentido podemos conjecturar que um processo de apropriação linguística, em particular, relativo a equações diferenciais ordinárias de primeira ordem foi se configurando no decorrer das seis atividades de Modelagem Matemática desenvolvidas. Os resultados da pesquisa indicam que a constituição de significado no interior de atividades de modelagem está associada à apropriação linguística dos alunos relativa às regras e técnicas que estão configuradas em jogos de linguagem específicos identificados nas atividades de Modelagem Matemática, sejam da situação-problema investigada, específicos da Matemática, ou ainda 
jogos de linguagem que mobilizam ferramentas como a tradução entre um jogo de linguagem e outro.

No âmbito da Modelagem Matemática na Educação Matemática, enfatizamos que os usos da linguagem e, em particular, a apropriação linguística, em atividades de Modelagem Matemática atuam como constituidores de significado, por meio da ação dos alunos com base em uma gramática que auxilia na mobilização de diferentes técnicas, regras e expressões, ora da Matemática, ora dos fenômenos investigados. Neste contexto, a experiência dos alunos com a Matemática, enfatizada por Pollak (2012), se constitui na formulação e resolução de problemas que se complementam na apropriação linguística de regras convencionadas em diferentes jogos de linguagem mobilizados em atividades de Modelagem Matemática.

\section{Referências}

ALMEIDA, L. M. W. Considerations on the use of mathematics in modeling activities. ZDM: the international journal on mathematics education. Berlim, v. 50, n. 3, p. 19-30, 2018.

CONDÉ, M. L. L. Wittgenstein: linguagem e mundo. São Paulo: Annablume, 1998.

GERRARD, S. Wittgenstein's philosophies of mathematics. Synthese, Londres, v. 87, p. 125-142, 1991.

GOTTSCHALK, C. M. C. A Natureza do Conhecimento Matemático sob a Perspectiva de Wittgenstein: algumas implicações educacionais. Caderno de História e Filosofia da Ciência. Campinas, v. 14, n. 2, p. 305-334, jul./dez. 2004.

GOTTSCHALK, C. M. A transmissão e produção do conhecimento matemático sob uma perspectiva wittgensteiniana. Cadernos Cedes, Campinas, v. 28, n. 74, p. 75-96, jan./abr. 2008.

GOTTSCHALK, C. M. C. O papel do método no ensino: da maiêutica socrática à terapia wittgensteiniana. EDT Educação Temática Digital. Campinas, v.12, n.1, p. 64-81, jul/dez. 2010.

MIGUEL, A. Is the mathematics education a problem for the school or is the school a problem for the mathematics education? RIPEM, v. 4, n. 2, p. 5-35, 2014.

MORENO, A. R. Descrição fenomenológica e descrição gramatical - ideias para uma pragmática filosófica. Revista olhar, São Carlos, v.4, n. 7, p. 93-139, jul./dez. 2003.

PALHARINI, B. N. A matemática em atividades de modelagem matemática: uma perspectiva wittgensteiniana. 2017. 316f. Tese (Doutorado em Ensino de Ciências e Educação Matemática) Universidade Estadual de Londrina, Londrina, 2017.

POLLAK, H. O. The interaction between Mathematics and other school subjects. In: New Trends in Mathematics Teaching. Volume IV. Paris: International Commission on Mathematical Instruction (ICMI), UNESCO, 1979. p. 232-248.

POLLAK, H. O. What is mathematical modeling? In: GOULD, H.; MURRAY, C. D. R.; SANFRATELLO, A. Mathematical Modeling Handbook. Bedfort: COMAP, 2012. Disponível em: $<$ https://www.comap.com>. Acesso em: 05 nov 2019. 
POLLAK, H. O. The Place of Mathematical Modelling in the System of Mathematics Education: Perspective and Prospect. In: STILLMAN, G.; BLUM, W.; BIEMBENGUT, M. S. (Ed.).

Mathematical Modelling in Education Research and Practice: cultural, social and cognitive influences. New York: Springer, 2015. p. 265-276.

SPINK, M. J. Práticas discursivas e produção de sentidos no cotidiano. Rio de Janeiro: Centro Edelstein de Pesquisas Sociais, 2013.

STILLMAN, G. A.; BROWN, J. P.; GEIGER, V. Facilitating Mathematisation in Modelling by Beginning Modellers in Secondary School In: STILLMAN, G.; BLUM, W.; BIEMBENGUT, M. S. (Ed.) Mathematical Modelling in Education Research and Practice: cultural, social and cognitive influences. New York: Springer, 2015. p. 93-104.

VILELA, D. S. Práticas matemáticas: contribuições sócio-filosóficas para a Educação Matemática. Zetetiké, Campinas, v. 17, n. 31, p. 191-211, jan./jun. 2009.

WITTGENSTEIN, L. Remarks on the foundations of mathematics. London: The MIT Press, 1996.

WITTGENSTEIN, L. Investigações Filosóficas. 8. ed. Petrópolis/Bragança Paulista: Vozes/Editora Universitária São Francisco, 2013. 